\title{
Addition of intrathecal dexamethasone to bupivacaine for spinal anesthesia in cesarean section
}

\author{
Original \\ Article \\ Mahamoud Ali Ahmed El-Shourbagy, Ahmed Mohamed Mammdouh, Mohamed \\ Esmat Abbass Shawky and Hamda Abdelhamid Omar Mohamed
}

Department of Obstetrics and Gynecology, Faculty of Medicine, Ain-Shams University, Egypt

\begin{abstract}
Background: Post-caesarean section pain is an important issue in obstetrics. Several studies have shown the importance of adequate postoperative analgesia on mobilization, rehabilitation and decreasing the length of hospital stay. Large amounts of opioid analgesic drugs are often required in the management of intense post-operative pain. However, this option is associated with many side effects.

Objective: The aim of the study was to assess the efficacy of adding dexamethasone to bupivacaine for spinal anesthesia in prolonging the duration and anesthetic effect in women undergoing cesarean section.

Patients and Methods: Populations of the study were comprised of 100 pregnant full term female planed for cesarean section. All patients had cesarean section under spinal anesthesia. Pain was assessed using $10 \mathrm{~cm}$ visual analogue scale (VAS) after 0,15, 30 min and 2, 4, 6 hours post-operatively and until the mother asked for an analgesic. The duration of sensory block as well as postoperative analgesia were calculated.

The study population had been randomized into 2 groups: The $1^{\text {st }}$ group $\mathrm{C}(\mathrm{n}=50$ women) included 50 women receiving intrathecal dexamethasone added to bupivacaine. The $2^{\text {nd }}$ group $B(n=50$ women) included 50 women receiving placebo which was added to intrathecal bupivacaine.

Results: This study has shown that the addition of intrathecal dexamethasone to bupivacaine significantly improved the duration of sensory block in spinal anesthesia as the duration of sensory block in the study group was $122+7.9$ minutes while in the control group it was $91.8+10.8$ minutes and $p<0.001$. Also, receiving time to VAS $>6$ and the first analgesic dose prescription in the case group was significantly longer than that in the control group $(P<0.001)$ as the pain free period in the study group was $434.3+43.8$ minutes while in the control group it was $215.3+40.3$ minutes. Also, the motor block duration in the study group was significantly prolonged when compared with control group $(p<0.01)$. There was no difference in onset time between the two groups and the addition of dexamethasone cause no complications.

Conclusion: This study has shown that the addition of intrathecal dexamethasone to bupivacaine significantly improved the duration of sensory block in spinal anesthesia without any changes in onset time and complications, and has increased the pain free period statistically.
\end{abstract}

Recommendations: Further studies are needed to evaluate the optimal dose of dexamethasone to be used in spinal anesthesia.

Key Words: Bupivacaine, cesarean section, intrathecal dexamethasone, spinal anesthesia

Received: 12 November 2018, Accepted: 10 December 2018

Corresponding Author: Hamda Abdelhamid Omar Mohamed, MSc., Department of Obstetrics and Gynecology, Faculty of Medicine, Ain-Shams University, Egypt, Tel.: 01061054922, E-mail: hamda_abdelhamid @yahoo.com

ISSN: 2090-7265, May 2019, Vol.9, No. 2

\section{INTRODUCTION}

Effective postoperative pain control is an essential component of the care of the surgical patient. Inadequate pain control may result in increased morbidity or mortality (Naziri et al., 2013).

Evidence suggests that surgery suppresses the immune system and that this suppression is proportionate to the invasiveness of the surgery (Murali Krishna et al., 2008). Good analgesia can reduce this deleterious effect. The advantages of effective postoperative pain management also include patient comfort and therefore satisfaction, earlier mobilization fewer pulmonary and cardiac complications, a reduced risk of deep vein thrombosis, faster recovery with less likelihood of the development of neuropathic pain, and reduced cost of care (Michael and Ramsay, 2000).

Spinal anesthesia is the most commonly used technique for cesarean section as it is very economical and easy to administer. It reduces mortality rate associated with cesarean section by sixteen times when compared with general anesthesia. Spinal anesthesia avoids the risks of general anesthesia such as aspiration of gastric contents, difficulty with airway management and infant respiratory distress (Naziri et al., 2013). 
At present, there is no drug able to control pain specifically without having side effects (Naziri et al., 2013). The use of corticosteroid compounds increases duration of anesthesia and analgesia in peripheral nerve blocks. In addition, intravenous (IV) and oral dexamethasone considerably alleviate postoperative pain (Bisgaard et al., 2003).

Epidural and intrathecal steroids are used to reduce chronic pain (Price et al., 2005). In some studies, intrathecal dexamethasone increased duration of sensory block and postoperative analgesia (Bani-Hashem et al., 2011).

Although intrathecal dexamethasone is used to control chronic pain; few studies have been conducted on the effects of sensory block and postoperative pain in patients undergoing surgery (Bani-Hashem et al., 2011).

\section{AIM OF THE WORK}

This study aims to assess the efficacy of adding dexamethasone to bupivacaine for spinal anesthesia in prolonging the duration and anesthetic effect in women undergoing cesarean section.

\section{PATIENTS AND METHODS}

Study design: Double blinded randomized controlled trial.

Setting: The study had been held at Ain-Shams Maternity Hospital in Labor Department.

\section{Population of the study:-}

One hundred pregnant healthy women who previously delivered by cesarean section and were planned for elective cesarean section had been recruited in this study. Written informed consents had been obtained from all study participants, after describing all aspects of the study. Patients had been randomly allocated to either case group who received $8 \mathrm{mg}$ intrathecal dexamethasone or control group who received $2 \mathrm{~mL}$ normal saline $(0.9 \%)$. One of each had been added to $8-12 \mathrm{mg}$ bupivacaine based on simple randomization process using generated random digit numbers by statistical package for the social sciences (SPSS).All study medication bottles had a unique bottle number and bar code for blinded dispensing. Neither the participants, nor the investigators responsible for following the participants, collecting the data and assessing the outcomes were aware of the intervention assignment.

\section{Sample size calculation:}

Sample size was calculated using PASS version 11 program, Results from a previous study showed that the mean duration of sensory block in the intervention group was $119+10.6$, while mean sensory block in control group was $89+8.3$, setting the type- 1 error (alpha) at $1 \%$ and power of study $90 \%$. Calculation according to these values produced a minimal sample size of 50 patients in each group (Parrington et al., 2013).

\section{Allocation and concealment:}

Individuals were randomized by a computer-based random number generator program and were distributed into two groups:

Group $(\boldsymbol{C})$ : included patients who received intrathecal dexamethasone.

Group (B): included patients who received placebo.

Sealed closed opaque envelops were designated for each patient, included their sequence and allocation to study groups with the type of intervention that the patient received either placebo or dexamethasone the medication was prepared and injected by an anesthesiologist who was not involved in the study to facilitate the double-blinding method. Envelopes were opened sequentially just before taking the spinal anesthesia. Active drug and placebo were concealed using litters denoted their identification.

\section{Inclusion criteria:}

- Age 20-40 years.

- Pregnant women who had planned for cesarean section.

- Gestational age of 38 weeks or more and planned for elective cesarean section.

- Living fetus.

- Any number of previous cesarean section.

- Intact amniotic membranes.

- No history of bleeding tendency.

- Body mass index 20- $29.9 \mathrm{~kg} / \mathrm{m} 2$.

- No previous uterine operations except cesarean section.

\section{Exclusion criteria:}

- Age $<20$ or $>40$ :

- Body mass index $<20$ or $>30$

- Refuse to participate after counseling.

- Contraindication to spinal anesthesia (coagulopathysignificant hypovolemia- systemic or local sepsisincreased intracranial pressure- local anesthetic or bupivacaine allergy). 
- High risk pregnancies as preeclampsia, any medical disorder (DM, cardiac disease or and thyroid disease).

- Contraindications to corticosteroids e.g. hypersensitivity

- Steroid medication one week before the operation.

- Chronic pain or daily intake of analgesic.

-Abnormal placentation e.g. placenta previa.

\section{Ethical issues:}

The study was conducted in accordance with the ethical committee protocols and informed consent procedures of Ain-Shams Maternity Hospital.

Before being admitted to the clinical study, the patient had consent to participate after the nature, scope and possible consequences had been explained in a form understandable to her (Form-1). An informed consent document, in Arabic language, contains all locally required elements and specifies who informed the patient (Form-2). After reading the informed consent document, the patient gave consent in writing. The patient's consent had been confirmed at the time of consent by the personally dated signature of the patient and by the personally dated signature of the person conducting the informed consent discussion.

If the patient was unable to read, oral presentation and explanation of the written informed consent form and information to be supplied to patients took place in the presence of an impartial witness, consent had confirmed at the time of consent orally and by the personally dated signature of the patient or by a local legally recognized alternative ( e.g. the patient thumb print ). The witness and the person conducting the informed consent discussion had signed and personally dated the consent document.

\section{Methods:}

Consent had taken from each patient after explanation of procedure completely.

\section{All patients subjected to:}

\section{a- Full history taking}

- Personal history (name -age -resident - occupation special habits - menstrual history).

- Obstetric history (first day of last menstrual period, estimated gestational age by date and antenatal care, any condition that complicate pregnancy e.g. preeclampsia , Diabetes Mellitus, placenta previa).
- Past history including medical (diseases-drugs) and surgical history (previous operation - blood transfusion).

\section{b- Full clinical examination:}

General examination including vital signs (pulseblood pressure - temperature) and body mass index.

Abdominal examination to detect; duration of pregnancy, fetal position and fetal heart sound, inspection of the back of the patient and the site of spinal injection.

\section{c- Full laboratory investigation:}

Blood group, $\mathrm{Rh}$, complete blood count, random blood sugar, viral marker for $\mathrm{HBV}, \mathrm{HCV}$, PT, and PTT.

\section{Patients of both groups who were planned for cesarean section distributed into two groups:}

Group C: included 50 patients who received intrathecal dexamethasone which will be added to bupivacaine.

Group B: included 50 patients who received placebo; $2 \mathrm{ml}$ normal saline which will be added to bupivacaine.

All the cesarean sections were done under observation of defined obstetric and anesthetic senior registrar.

\section{Technique:}

- On arrival to operation room standard monitoring was applied with non-invasive blood pressure measurement, electrocardiography and pulse oximeter.

- Before surgery, urinary catheter was introduced.

- Each participant received $10 \mathrm{ml} / \mathrm{kg}$ intravenous fluid in the form of Hartmann solutions within 15 min as preload.

- Patient sits in sitting position.

- Low back was prepared and draped in sterile fashion with povidone iodine $10 \%$.

- After using 3-5 ml lidocaine 1\%, skin wheal of local anesthetic was placed at L4-L5 or L5-S1 intervertebral space using a pencil point spinal needle (size27G).

- The introducer of the spinal needle was grasped and the needle was introduced through it carefully till loss of resistance and sensing dural puncture.

- After insuring adequate CSF was coming through the needle 8-12 $\mathrm{mg}$ of bupivacaine was injected added to them either $2 \mathrm{ml}$ normal saline or $8 \mathrm{mg}$ dexamethasone. 
- The sensory block level was assisted every 30 seconds for 20 minutes; then it was evaluated in time required until a 4 sensory level regression from highest level or to the end of the surgery. Onset time was defined from the time of injection of drugs into the intrathecal space to the peak of sensory and motor block (highest dermatome level) and the duration of sensory block was defined from peak of sensory block up to the time

- when the patients feel pain in the field of surgery and can clearly feel any cold object on $4^{\text {th }}$ sensory level regression.

\section{Sensory block assessment:}

- Explain procedure and purpose to the woman.

- Wrap an ice cube in tissue/paper towel leaving part exposed

- Place ice on an area well away from the possible dermatome cover (eg face or forearm) and ask them to tell you how cold it feels to them.

- Apply the ice to an area likely to be blocked on the same side of the body and ask the woman "Does this feel the same cold as your face/arm or different?" woman may report the ice feeling colder, warmer or the same.

- Apply the ice to areas above and below this point until it's clear at which level the top and the bottom of the block is.

- Repeat the procedure on the opposite side of the body.

- Document the blocked dermatomes on the Pain observation chart Record both the upper and lower limits of the block: e g. T7-L1 L=R or R: T7-L1 L: T10-L2

- Perform assessment at commencement of each time pain would be evaluated. (Fettes et al., 2009).

- Motor assessment by Modified Bomage scale $=1$ MBS with MBS 1-6 as 1=complete motor block, $2=$ almost complete motor block (patient able to move feet), 3 = partial motor block; patient able to move the knee, $4=$ detectable weakness of hip flexion, $5=$ no detectable weakness of hip flexion as she can keep the leg raised for at least 10 seconds, $6=$ no motor weakness.

- The patient was turn to supine position with left lateral displacement of the uterus to avoid supine hypotension syndrome.

- The spread of sensory analgesia was assessed using skin prick method.

- Hypotension more than $30 \%$ of basal blood pressure was treated by ephedrine $5 \mathrm{mg}$ IV in incremental doses.

- Bradycardia was treated by atropine if needed.

- $4 \mathrm{~L} / \mathrm{min} \mathrm{O} 2$ by nasal prong was connected to the patient.

- After delivery of baby, oxytocin 10 units/liter was infused.
- During the following -up period severity of pain was monitored at $0,15,30,60 \mathrm{~min}$ and 2 (in recovery room), 4, $6 \mathrm{hr}$ (in surgery ward) after operation.

- Severity of pain based on visual analogue scale (VAS) was measured using a $10 \mathrm{~cm}$ ruler according to the self-reporting by patients. In this method, patient was asked to indicate zero in case of having no pain and 10 if she has the most severe pain. For pain, score $<4$ was considered as mild, 4-6 as moderate and 7-10 as severe (Elzayyat et al., 2014).

\section{Outcome measures:}

\section{* Primary outcome:}

Assessment of the duration of sensory block (was defined from peak of sensory block up to 4 sensory level regressions: regain felling of cold object at that site or when the patients feel pain in the field of surgery). After 4 dermatome block, pain assessment was done using the visual analogue pain scale (VAS) for assessment of duration of analgesia (request for analgesic).

0-10 Numeric Pain Rating Scale

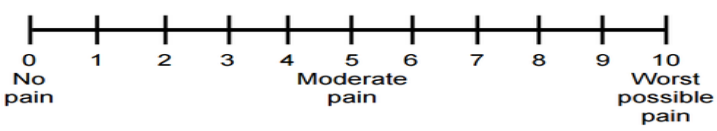

This scale, patient was asked as follow "0" means no pain and "10" means worst pain you can imagine, what was it like during operation? How is it now?" pain was classified (Erin et al., 2007) into 4 levels:

-No pain (0)

-Slight pain ( 1-3 )

-Moderate ( 4 - 6 )

-Severe(7-10)

\section{* Secondary outcome:}

Repeated postoperative local and general examination of patient allowed discovering any adverse effect. Data about possible side effects (nausea, vomiting, hypotension, bradycardia, shivering, headache or dyspnea) was collected for statistical evaluation. Onset time was defined from the time of injection of drugs into the intrathecal space to the peak of sensory and motor block (highest dermatome level).

\section{STATISTICAL ANALYSIS}

The collected data was revised, coded, tabulated and introduced to a PC using Statistical Package for Social Science (SPSS 15.0.1 for windows; SPSS Inc, 
Chicago, IL, 2001). Data was presented and analysis was done according to the type of data obtained for each parameter.

\section{Descriptive statistics:}

- Mean.

- Standard deviation $( \pm \mathrm{SD})$.

- Minimum and maximum values (range) for numerical data.

- Frequency and percentage of non-numerical data.

\section{Analytical statistics:}

- Independent-Samples T Test was used to assess the statistical significance of the difference between two study group means.

- ANOVA test was used to assess the statistical significance of the difference between more than two study group means.
- Correlation analysis (using Pearson's method): To assess the strength of association between two quantitative variables. The correlation coefficient denoted symbolically " $r$ " define the strength and direction of the linear relationship between two variables.

- Chi-Square test was used to examine the relationship between two qualitative variables.

- Linear regression: It was used to test and estimate the dependence of a quantitative variable (e.g. intraoperative pain) based on its relationship to one or more independent variables (Age or Gestational age).

- P- value: level of significance $\mathrm{P}>0.05$ : Non significant (NS). $\mathrm{P}<0.05$ : Significant $(\mathrm{S})$. $\mathrm{P}<0.01$ : Highly significant (HS).

- Data was graphically represented using PowerPoint program.

\section{RESULTS}

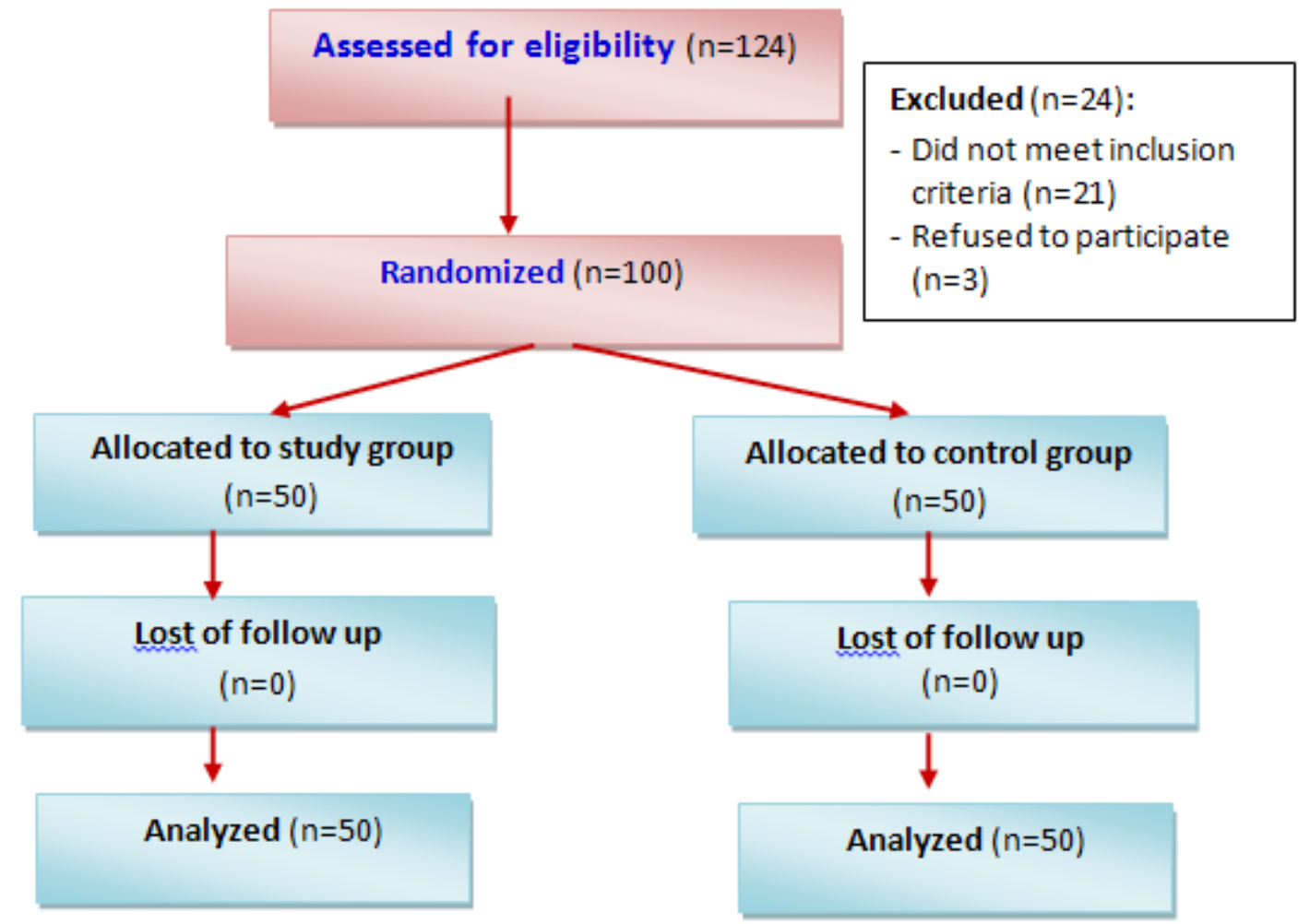

Fig 1: Consort, Patient flow chart. 
All patients $(n=100)$ completed the study. The cause of exclusion was due to multiple pregnancy, medical disorder or body mass index $>30$.

Table 1: Demographic characteristics among the studied groups

\begin{tabular}{lcccc}
\hline Variables & Measures & $\begin{array}{c}\text { Study } \\
(\mathrm{N}=50)\end{array}$ & $\begin{array}{c}\text { Control } \\
(\mathrm{N}=50)\end{array}$ & $P$ \\
\hline Age & Mean $\pm \mathrm{SD}$ & $30.3 \pm 3.3$ & $31.1 \pm 3.7$ & 0.272 \\
years $)$ & Range & $24.0-38.0$ & $25.0-40.0$ & \\
BMI (kg/ & Mean $\pm \mathrm{SD}$ & $27.5 \pm 1.5$ & $27.4 \pm 1.4$ & 0.891 \\
$\mathrm{~m} 2)$ & Range & $24.0-30.0$ & $24.2-30.0$ & \\
& Mean $\pm \mathrm{SD}$ & $2.3 \pm 0.7$ & $2.4 \pm 0.7$ & 0.321 \\
Parity & Range & $1.0-4.0$ & $1.0-4.0$ & \\
Previous & Mean $\pm \mathrm{SD}$ & $1.3 \pm 0.6$ & $1.2 \pm 0.5$ & 0.705 \\
CS & Range & $1.0-3.0$ & $1.0-3.0$ & \\
GA & Mean $\pm \mathrm{SD}$ & $39.6 \pm 0.6$ & $39.3 \pm 0.8$ & 0.100 \\
(weeks) & Range & $38.0-41.0$ & $37.0-41.0$ & \\
\hline
\end{tabular}

Independent t-test

No significant difference between the studied groups regarding demographic characteristics; age, body mass index, gestational age or parity.

There was no signification difference in sensory level, and onset time of the sensory block between two groups. The onset time of sensory block was $5.3 \pm 1.7$ minutes for the case group and $5.9 \pm 1.9$ minutes for the control group. The maximum sensory level was between T 4 and T 10 in both groups and there was no significant difference $(P=0.136)$

Table 2: Onset time (minutes): duration from injection of anesthetic drug tell peak sensory block among the studied groups

\begin{tabular}{lccc}
\hline Measures & $\begin{array}{c}\text { Study } \\
(\mathrm{N}=50)\end{array}$ & $\begin{array}{l}\text { Control } \\
(\mathrm{N}=50)\end{array}$ & $\wedge P$ \\
\hline Mean $\pm \mathrm{SD}$ & $5.3 \pm 1.7$ & $5.7 \pm 1.9$ & 0.136 \\
Range & $4.0-7.0$ & $4.0-7.0$ & \\
\hline
\end{tabular}

^Independent t-test, ${ }^{*}$ Significant, CI: Confidence interval

Table 2 shows that: No significant difference between the studied groups regarding onset time.

Sensory block duration; time from peak of sensory block up to 4 sensory level regressions(feel cold objects) or when the patients feel pain at site of incision, in the case group was $122.4 \pm 7.9$ minutes and in the control group was $91.8+8$ minutes which was significantly higher in the case group $(P<0.001)$.

Table 3: Duration of sensory block (minutes); among the studied groups

\begin{tabular}{lccc}
\hline Measures & $\begin{array}{c}\text { Study } \\
(\mathrm{N}=50)\end{array}$ & $\begin{array}{c}\text { Control } \\
(\mathrm{N}=50)\end{array}$ & $\wedge P$ \\
\hline Mean $\pm \mathrm{SD}$ & $122.4 \pm 7.9$ & $91.8 \pm 10.8$ & $<0.001^{*}$ \\
Range & $103.0-147.0$ & $70.0-113.0$ & \\
\multicolumn{4}{c}{ Impact of dexamethasone on sensory block duration } \\
$\begin{array}{l}\text { Items } \\
\text { Duration } \\
\text { prolongation }\end{array}$ & Mean $\pm \mathrm{SD}$ & $95 \% \mathrm{CI}$ \\
\hline
\end{tabular}

${ }^{\wedge}$ Independent t-test, ${ }^{*}$ Significant, CI: Confidence interval
Table 6 shows that duration of sensory block was significantly longer in study group than in control group.

The duration of analgesia was $434.3 \pm 43.8$ minutes in the case group; whereas it was $215.3 \pm 40.3$ minutes in the control group $(P<0.001)$ i.e pain-free period in the case group was more than that in the control group $(P<0.001)$.

Table 4: Duration of pain-free period (minutes) duration of analgesia, request for analgesic or VAS $>6$ :time from peak of sensory block tell the mother ask for analgesic, among the studied groups

\begin{tabular}{lccl}
\hline Measures & $\begin{array}{c}\text { Study } \\
(\mathrm{N}=50)\end{array}$ & $\begin{array}{c}\text { Control } \\
(\mathrm{N}=50)\end{array}$ & $\wedge P$ \\
\hline Mean $\pm \mathrm{SD}$ & $434.3 \pm 43.8$ & $215.3 \pm 40.3$ & $<0.001^{*}$ \\
Range & $324.0-554.0$ & $119.0-301.0$ &
\end{tabular}

Impact of dexamethasone on pain-free period duration

\begin{tabular}{lcc} 
Items & Mean \pm SD & $95 \%$ CI \\
$\begin{array}{l}\text { Duration } \\
\text { prolongation }\end{array}$ & $219.0 \pm 8.4$ & $202.3-235.7$ \\
\hline
\end{tabular}

${ }^{\wedge}$ Independent t-test, ${ }^{*}$ Significant, CI: Confidence interval

Table 4 shows that: Duration of pain-free period was significantly longer in study group than in control group.

Receiving time to VAS $>6$ and the first analgesic dose prescription in the case group was significantly longer than that in the control group $(P<0.001)$.

Table 5: Pain perception (VAS-10) among the control and study group

\begin{tabular}{|c|c|c|c|c|}
\hline Time & Measures & $\begin{array}{c}\text { Study } \\
(\mathrm{N}=50)\end{array}$ & $\begin{array}{l}\text { Control } \\
(\mathrm{N}=50)\end{array}$ & $\wedge P$ \\
\hline \multirow{2}{*}{ Minute-0 } & Mean \pm SD & $0.3 \pm 0.4$ & $0.3 \pm 0.6$ & \multirow{2}{*}{0.429} \\
\hline & Range & $0.0-1.0$ & $0.0-2.0$ & \\
\hline \multirow{2}{*}{ Minute-15 } & Mean \pm SD & $0.5 \pm 0.5$ & $0.7 \pm 0.7$ & \multirow{2}{*}{0.139} \\
\hline & Range & $0.0-2.0$ & $0.0-2.0$ & \\
\hline \multirow{2}{*}{ Minute-30 } & Mean \pm SD & $1.1 \pm 0.6$ & $1.4 \pm 0.5$ & \multirow{2}{*}{$0.008 *$} \\
\hline & Range & $0.0-2.0$ & $0.0-2.0$ & \\
\hline \multirow{2}{*}{ Minute- 60} & Mean \pm SD & $1.4 \pm 0.5$ & $1.9 \pm 0.6$ & \multirow{2}{*}{$<0.001^{*}$} \\
\hline & Range & $1.0-2.0$ & $1.0-3.0$ & \\
\hline \multirow{2}{*}{ Minute-120 } & Mean \pm SD & $1.9 \pm 0.6$ & $2.5 \pm 0.7$ & \multirow{2}{*}{$<0.001 *$} \\
\hline & Range & $1.0-3.0$ & & \\
\hline
\end{tabular}

Impact of dexamethasone on pain reduction

Time Mean \pm SD $\quad 95 \%$ CI

$\begin{array}{lll}\text { Minute- } 0 & 0.1 \pm 0.1 & -0.1-0.3\end{array}$

Minute-15 $\quad 0.2 \pm 0.1 \quad-0.1-0.4$

$\begin{array}{lll}\text { Minute-30 } & 0.3 \pm 0.1 & 0.1-0.5\end{array}$

$\begin{array}{lll}\text { Minute-60 } & 0.4 \pm 0.1 & 0.2-0.6\end{array}$

$\begin{array}{lll}\text { Minute-120 } & 0.6 \pm 0.1 & 0.3-0.9\end{array}$

${ }^{\wedge}$ Independent t-test, \#Paire dt-test, ${ }^{*}$ Significant, CI: Confidence interval

Table 5 shows that: No significant difference between the studied groups regarding

Pain score at minutes 0 and 15 . Pain score at minutes 30,60 and 120 were significantly lower in study group than in control group. 


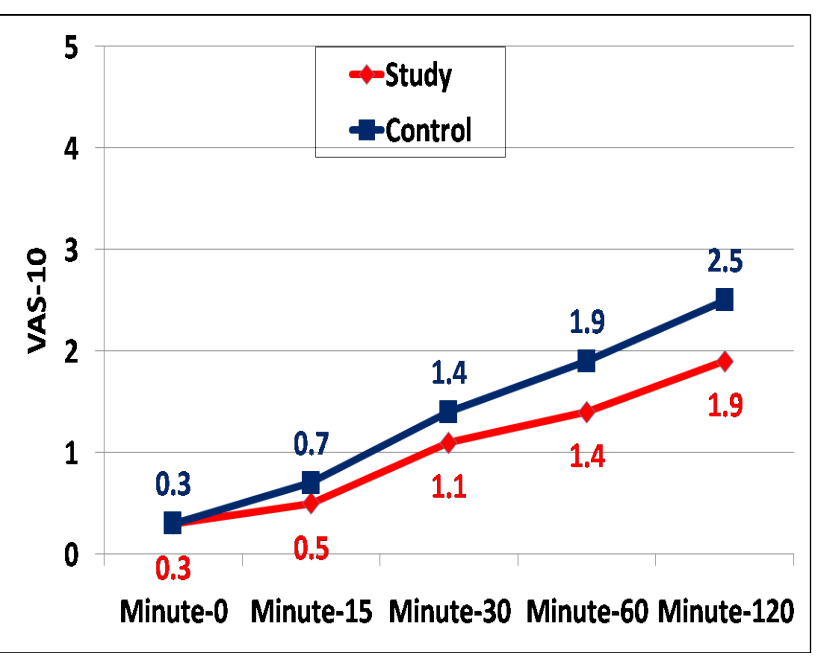

Fig. 2: Pain perception (VAS-10) among the studied groups

Table (6): Duration of motor block (minutes) among the studied groups

\begin{tabular}{lccc}
\hline Measures & $\begin{array}{c}\text { Study } \\
(\mathrm{N}=50)\end{array}$ & $\begin{array}{c}\text { Control } \\
(\mathrm{N}=50)\end{array}$ & $\wedge P$ \\
\hline Mean $\pm \mathrm{SD}$ & $137.1 \pm 7.7$ & $106.3 \pm 11.3$ & $<0.001^{*}$ \\
\multicolumn{2}{c}{\begin{tabular}{c} 
Range \\
\multicolumn{1}{c}{ Impact of dxamethasone on motor block duration }
\end{tabular}} \\
$\begin{array}{l}\text { Items } \\
\begin{array}{l}\text { Duration } \\
\text { prolongation }\end{array}\end{array}$ & $30.7 \pm 1.9$ & $95 \% \mathrm{CI}$ \\
\hline
\end{tabular}

${ }^{\wedge}$ Independent t-test, ${ }^{*}$ Significant, CI: Confidence interval

Table 6 shows that : Duration of motor block was significantly longer in study group than in control group.

Hypotension was mild to moderate in both groups and was not different.

Other complications such as headache, palpitation, bradycardia, nausea, and vomiting were not different between the two groups (Table 7) and no neurologic deficit was observed in any patients.

Table 7: Side effects among the studied groups

\begin{tabular}{|c|c|c|c|c|}
\hline Side effects & $\begin{array}{c}\text { Study } \\
(\mathrm{N}=50)\end{array}$ & $\begin{array}{l}\text { Control } \\
(\mathrm{N}=50)\end{array}$ & $\wedge \mathrm{P}$ & $\begin{array}{c}\mathrm{RR} \\
(95 \% \mathrm{CI})\end{array}$ \\
\hline $\begin{array}{l}\text { Nausea and } \\
\text { vomiting }\end{array}$ & $\begin{array}{c}10.0 \\
(10.0 \%)\end{array}$ & $\begin{array}{c}24.0 \\
(24.0 \%)\end{array}$ & 0.062 & $\begin{array}{c}0.54 \\
(0.25-1.16)\end{array}$ \\
\hline Hypotension & $\begin{array}{c}24.0 \\
(24.0 \%)\end{array}$ & $\begin{array}{c}28.0 \\
(28.0 \%)\end{array}$ & 0.648 & $\begin{array}{c}0.90 \\
(0.56-1.44)\end{array}$ \\
\hline Bradycardia & $\begin{array}{c}26.0 \\
(26.0 \%)\end{array}$ & $\begin{array}{c}20.0 \\
(20.0 \%)\end{array}$ & 0.476 & $\begin{array}{c}1.18 \\
(0.77-1.80)\end{array}$ \\
\hline Shivering & $\begin{array}{c}42.0 \\
(42.0 \%)\end{array}$ & $\begin{array}{c}36.0 \\
(36.0 \%)\end{array}$ & 0.539 & $\begin{array}{c}1.13 \\
(0.77-1.68)\end{array}$ \\
\hline $\begin{array}{l}\text { Headache/ } \\
\text { dyspnea }\end{array}$ & $\begin{array}{c}58.0 \\
(58.0 \%)\end{array}$ & $\begin{array}{c}62.0 \\
(62.0 \%)\end{array}$ & 0.683 & $\begin{array}{c}0.92 \\
(0.62-1.37)\end{array}$ \\
\hline
\end{tabular}

${ }^{\wedge}$ Chi square test, RR: Relative risk, ${ }^{*}$ Significant, CI: Confidence interval

Table 7 shows that: Side effects were non-significantly different among the studied groups

\section{DISCUSSION}

In the current study, the duration of analgesia of hyperbaric bupivacaine alone was compared with the duration of analgesia of hyperbaric bupivacaine in combination with dexamethasone during spinal anesthesia, employed for elective caesarean section, on one hundred pregnant women. The collected data showed that instillation of combination of dexamethasone and hyperbaric bupivacaine provided more duration of analgesia $434.3 \pm 43.8$ minutes as compared to hyperbaric bupivacaine alone $215.3 \pm 40.3$ minutes with p-value $<0.001$ which is statically significant and the supplementation of spinal bupivacaine with $8 \mathrm{mg}$ dexamethasone significantly prolonged sensory block $122.4 \pm 7.9$ compared with intrathecal bupivacaine alone $91.8 \pm 10.8$, also the motor block duration in the study group $(137.1+7.7$ minute) was significantly prolonged when compared with control group $(106.3+11.3$ minutes $) ;(p<0,01)$. There was on effects on the onset time of sensory block.

These results are in agreement with those of the study that compared the duration of analgesia of hyperbaric bupivacaine alone and in combination with dexamethasone during spinal anaesthesia employed for elective caesarean section, in 60 pregnant women. The collected data showed that the adjuvant combination of dexamethasone and hyperbaric bupivacaine provided more duration of analgesia 391 \pm 25.51 minutes as compared to hyperbaric Bupivacaine alone $179.43 \pm 23.32$ minutes with $p$-value $<0.05$ which was considered statically significant (Fayyaz et al., 2015).

Another study went in agreement with the current study, it included 50 patients scheduled for orthopedic surgery under spinal anesthesia. The patients were randomly allocated to receive hyperbaric bupivacaine with normal saline (control group) or hyperbaric bupivacaine plus dexamethasone (case group) intrathecally. They found sensory block duration in the case group (119 \pm 10.69 minutes) was significantly higher in the case group $(89.44 \pm 8.37)$ with $(P<0.001)$ (Bani-Hashem et al., 2013).

In a previous double-blinded, three arm study conducted on 20 patients for each arm, were scheduled for lower abdominal operations. They were administered intrathecal bupivacaine injection and randomly divided into one of three groups: in which administered additional; saline, dexamethasone or dexmedetomidine (selective $\alpha 2$-adrenergic agonist) intrathecally. As in the current study addition of dexamethasone produced longer duration of postoperative analgesia when it compared with the control group also prolonged the duration of sensory block postoperatively. But dexmedetomidine 
produced longer duration of analgesia compared with dexamethasone. That was presented in; time to two-segment regression was significantly longer in the dexmedetomidine group compared with the control group $(P<0.001)$ and the dexamethasone group $(P=0.025)$, and it was significantly longer in the dexamethasone group compared with the control group $(P<0.001)$. Dexmedetomidine was associated with a faster onset and longer duration of the sensory blockade compared with dexamethasone. In addition dexmedetomidine causes longer duration of motor block.

Like this study, frequency of adverse events, was limited in all groups. The cost effectiveness of dexmedetomidine versus dexamethasone is an issue of conflict, as tangible cost of dexmedetomidine is higher than dexamethasone; yet the intangible costs (hospital stay, wound infection, nausea and vomiting, ICU stay if needed, antibiotics .... etc.) need to be considered in drug selection (Elzayyat et al., 2014).

The sensory block duration also had been observed in a study compared intrathecal dexamethasone with epinephrine as adjuvants to lidocaine in cesarean section. Onset of sensory block in lidocaine group was considerably shorter than dexamethasone and epinephrine groups. Duration of sensory block in the control group, dexamethasone group, and epinephrine group were $64.16 \pm 7.99 \mathrm{~min}, 74.79 \pm 12.78 \mathrm{~min}$, and $99.30 \pm 10.93 \mathrm{~min}$, respectively $(p<0.001)$ (Naziri, 2012).

In other study, male patients scheduled for transurethral prostatectomy under spinal anesthesia in which three equal groups received dexamethasone, meperidine or normal saline, in addition to hyperbaric bupivacaine. Dexamethasone group had better sensory and motor block characters and duration of postoperative analgesia in comparable with the control group $(p<0.001)$. Dexamethasone and meperidine groups have better sensory and motor block characters and duration of post-operative analgesia in comparable with the control group. Patients in meperidine group experienced more sedation and pruritus. These factors may add to those patients in dexamethasone group reported higher satisfaction scores. Patients in dexamethasone group also experienced less hemodynamic events and no sedation (Moeen and Moeen, 2017).

In line with this study; the study of (Movafegh et al., 2005) compared lidocaine alone and the addition of ether dexamethasone or epinephrine to lidocaine for spinal anesthesia. The addition of dexamethasone to lidocaine for spinal anesthesia provided significant prolongation of sensory and motor block in comparison with plain lidocaine and there is no difference between dexamethasone-lidocaine and epinephrine lidocaine in sensory and motor block duration. Consequently, the onset time of sensory and motor blockade were similar among these three groups.

In a study on forty-four patients underwent unilateral inguinal herniorrhaphy; compared addition of dexamethasone or tramadol to epidural bupivacaine as regard their effect on the duration of postoperative analgesia which was found to be significantly longer in the dexamethasone group than in the tramadol group ( $p<0.001)$ (Shrestha et al., 2007).

Combination of dexamethasone plus bupivacaine was found in another study to increased duration of analgesia in ultrasound guided interscalene brachial plexus block. The opioid requirement in oxycodone equivalency was lower in the dexamethasone group than in the control group for the first 24 hours and similar thereafter (Neal et al., 2010).

Also, prolongation of analgesia had been observed with addition of dexamethasone to levobupivacaine when used for interscalene brachial plexus block Hefni et al. (2012). Another study randomized 129 women scheduled for laparoscopic hysterectomy to receive placebo, dexamethasone $5 \mathrm{mg}$ (D5), $10 \mathrm{mg}$ (D10), or $15 \mathrm{mg}$ (D15) IV before the induction of anesthesia. Until the first postoperative morning, postoperative pain was managed with IV oxycodone using patient-controlled analgesia. The amounts of the analgesics were recorded for 3 days after surgery. The total dose of oxycodone (0-24 $\mathrm{h}$ after surgery) was smaller in the D15 $(0.34 \mathrm{mg} / \mathrm{kg}[0.11-0.87])$ group than in the placebo group $(0.55 \mathrm{mg} / \mathrm{kg}[0.191 .13-])(P=0.003)$. Reduction in consumption of oxycodone was observed after laparoscopic hysterectomy when intravenous dexamethasone was administered before induction of anesthesia (Jokela et al., 2009).

On the other hand, the study failed to find a prolonged analgesic effect of steroids postoperatively used epidural methylprednisolone as an additive to bupivacaine for pain relief after lumbar discectomy and found no difference in analgesic duration compared to bupivacaine alone (Lotfinia, 2007).

In this study, a dose of $8 \mathrm{mg}$ dexamethasone in spinal anesthesia because administration of this dose was deemed to be safe in adults; however, additional studies must be done to determine the optimal dose of intrathecal dexamethasone. 


\section{CONCLUSION AND RECOMMENDATION}

This study has shown that the addition of intrathecal dexamethasone to bupivacaine significantly improved the duration of sensory block in spinal anesthesia without any changes in onset time and complications, and has increased the pain free period statistically.

Further studies are needed to evaluate the optimal dose of dexamethasone to be used in spinal anesthesia.

\section{CONFLICT OF INTEREST}

There are no conflicts of interest.

\section{REFERENCES}

1. Bani-Hashem N, Hassan-Nasab B, Alijan Pour E, (2011): Addition of intrathecal dexamethasone to Bupivacaine for spinal anesthesia in orthopedic surgery. Saudi J Anaesth; 5(4): 382-6

2. Bisgaard T, Klarskov B, Kehlet $\mathrm{H}$ and Rosenberg J. (2003): Preoperative dexamethasone improves surgical outcome after laparoscopic cholecystectomy: A randomized doubleblind placebo-controlled trial. Ann Surg; 238(5): 651-60.

3. Elzayyat NS, Nagy HI, Girgis K (2014): Comparing the effect of adding dexmedetomidine versus dexamethasone on prolonging the duration of intrathecal bupivacaine in lower abdominal operations. Ain Shams Journal of Anesthesiology. $7(3): 388-392$

4. Hefni,M. S.Mahmoud, and A. A. A. Al Alim(2014): Epidural dexamethasone for postoperative analgesia in patients undergoing abdominal hysterectomy: a dose ranging and safety evaluation study," Saudi Journal of Anaesthesia, vol. 8, no. 3, pp. 323-327.

5. Jokela RM, Ahonen JV, Tallgren MK, Marjakangas PC, Korttila KT. (2009): The effective analgesic dose of dexamethasone after laparoscopic hysterectomy. Anesth Analg;109:607-15.

6. Lotfinia I, Khallaghi E, Meshkini A, Shakeri M, Shima M, Safaeian A. (2007): Interaoperative use of epidural methylprednisolone or bupivacaine for postsurgical lumbar discectomy pain relief: A randomized, placebo-controlled trial. Ann Saudi Med. 2007;27:279-83.

7. Michael AE and Ramsay, MD (2000): Acute postoperative pain management. BUMC Proceedings.; 13:244-247.

8. Moeen SM, Moeen AM. (2017): Intrathecal dexamethasone vs. meperidine for prevention of shivering during transurethral prostatectomy: a randomized controlled trial. Acta Anaesthesiol Scand.; 61(7):749-757.

9. Movafegh A, Razazian M, Hajimaohamadi F, Mysamie A. (2006): Dexamethasone added to lidocaine prolongs axillary bracial plexus blockage. Anesth Analg;102:263-7.

10. Murali Krishna T, Panda NB, Batra YK and Rajeev S. (2008): Combination of low doses of intrathecal ketamine and midazolam with bupivacaine improves postoperative analgesia in orthopaedic surgery. Eur J Anaesthesiol; 25(4): 299-306.

11. Naziri F, Rabiee M, Nadeia Banihashem, Keyvan Hosseinjanzadeh, Zeiba Shirkhani, S. Sedigheh Solimanian2 (2013): Comparative Study of Intrathecal Dexamethasone with Epinephrine as Adjuvants to Lidocaine in Cesarean Section. ZJRMS 2013; 15(9): 23-26.

12. Neal JM, Bernards CM, and Butterworth JF (2010): ASRA practice advisory on local anesthetic systemic toxicity. Reg Anesth Pain Med; 35:152-61.

13. Price C, Arden N, Coglan L and Rogers P. (2005): Cost-effectiveness and safety of epidural steroids in the management of sciatica. Health Technol Assess; 9(33): 1-58.

14. Shrestha B. R., Maharjan SK, Shrestha S. et al (2007): Comparative study between tramadol and dexamethasone as an admixture to bupivacaine in supraclavicular brachial plexus block," Journal of the NepalMedical Association. 46(168):158-164. 